\title{
Differences in Roughness Parameter Values from Skid and Skidless Contact Stylus Profilometers
}

\author{
Karol Grochalski ${ }^{*}$, Michał Mendak', Michał Jakubowicz', Bartosz Gapiński', \\ Natalia Swojak', Michał Wieczorowski', Aleksandra Krawczyk² \\ 1 Poznan University of Technology, Institute of Mechanical Technology, Division of Metrology and Measurement \\ Systems, ul. Piotrowo 3, 60-965 Poznan, Poland \\ 2 Huta Bankowa Inc., ul. Sobieskiego 24, 41-300 Dąbrowa Górnicza, Poland \\ * Corresponding author's email: karol.grochalski@put.poznan.pl
}

\begin{abstract}
Contact stylus profilometry is the leading surface texture measuring method in many manufacturing industries. For years it has been unmatched in terms of accuracy and reliability. Advancements in technology have led to the improvements in the profilometer design. A stylus can either have a built in skid or be skidless. In this study, the influence of skid on the measurement accuracy and repeatability was evaluated. Four different contact stylus profilometers were used to measure three standard roughness artifacts each. Every set of measurements consisted of 50 repetitions of the same profile, with the same parameters. Out of these profiles, five roughness parameters were calculated and were subjected to a statistical analysis. Relative errors of these parameters were also considered and presented individually for each roughness standard. Researchers found differences in the measurement results dispersion of various roughness parameters between the three roughness standards. The presented results of the measurements clearly indicated that there is a dispersion of the obtained values for the older type of contact stylus profilometer (P1, skid). The skidless portable devices, $\mathrm{P} 2$ and $\mathrm{P} 3$, have better measurement resolution, which results in a noticeably lower dispersion of measured values. A tabletop, stationary device utilizes a skidless measuring probe. It has both the best resolution and the highest rigidity, which results in the lowest dispersion of measured values. The lowest relative error of the Ra parameter was determined for the P2 device (9.2\%) and the highest was determined for the $\mathrm{P} 3$ device $(72.6 \%)$.
\end{abstract}

Keywords: contact profilometer, portable profilometer, roughness parameters skid devices, skidless devices

\section{INTRODUCTION}

Improving the quality of the manufacturing process is the direct effect of perfecting the means of quality control (QC) of manufactured elements, both in a macro and micro scale. It requires the simultaneous advancement of company QC divisions, as well as adopting more and more advanced measurement techniques and technologies. One of the most important parameters describing the quality of a part is its surface texture [1] in the case of two parts in contact [2] where they may be subjected to significant wear. This was shown in many publications for different applications, including workpieces [3, 4], running-in process [5], type of machining [6] or materials [7].

A well designed surface texture, with specific roughness parameters will have superior tribological characteristics. The manufacturing process and surface finishing technique determines the surface texture of a part [8]. A broad concept of surface texture is an important factor in evaluating surface integrity, which belongs to a set of basic characteristics describing the quality of manufactured parts. It has a direct impact on the durability and usability of a part. A set of all the parameters describing surface deviations is called the Geometric Surface Structure. These deviations include roughness, waviness and form deviation. 
They can be divided into three groups, large scale deviations (form), and small scale (waviness and roughness). A typical procedure to analyse surface texture is to measure several profiles, out of which several parameters can be calculated. However, the most information-dense method is 3D (surface) measurement $[9,10]$. There are several, widely accepted, ways of surface filtration, which allow just the wavelengths (scales) of interest to be extracted. This was shown by Myshkin et al. [11] and Teague et al. [12], who carried out the research on the issues related to microscale filtration in contact profilometry.

Surface asperities are the smallest scale features in Dimensional Metrology (DM), thus requiring specialized instruments and sophisticated acquisition methods capable of performing the measurement [13]. Unlike in other areas of DM, no geometrical features of the part are evaluated here, but its surface features in a specific area are analysed using a set of parameters and functions.

The literature analysis indicates an increase of interest in the matters of surface topography measurement credibility and accuracy. In the case where contact stylus profilometry is either difficult or is not a preferred method, then contactless technology, such as confocal or interferometric is used. This was reported by many researchers, including De Groot [14], Foreman et al. [15], Gomez et al. [16], Kucharski et al. [17] and Grochalski et al. [18]. The issues related to non-contact surface measurement versus stylus measurements were presented e.g. in [19]. As of now, the most widely used method in industry is still contact stylus profilometry, which utilizes a rigid stylus with a diamond tip that is traversed over a measured surface. This method has been well studied; however, it is sensitive to certain interferences, including vibrations, thermal fluctuations, and stylus tip errors. The work on these issues is presented by many authors $[20,21,22]$. Modern QC demands the use of measurement devices that give the most accurate feedback.

a)

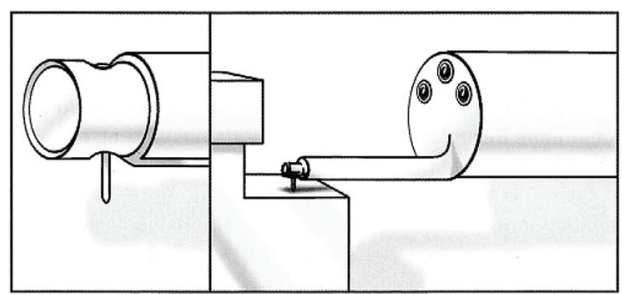

\section{MEASUREMENT METHODS IN CONTACT STYLUS PROFILOMETRY}

Contact profilometry utilizes a data acquisition system, in which the measuring probe consists of the arm, which ends with a stylus, usually a diamond tip. During the measurement, the stylus is traversed across the surface. The vertical movement of the stylus, which resembles the height changes as it moves over the surface features, is converted into a measurement signal as a function of position.

It is the most common method of surface texture measurement in the manufacturing industry. When the surface is intersected by a perpendicular plane, in this case the plane of the stylus probe, an intersection profile of surface irregularities emerges. A device capable of performing a measurement in this manner is called a profilometer [23]. There are two basic types of profilometers: portable and tabletop. Portable devices are relatively small, but their measurement capabilities are limited, whereas stationary devices enable measurement of all components of surface irregularities.

A contact profilometer utilizes three measurement systems, mechanical - which includes motorized stage, stylus probe etc., electronics - controllers, main computing unit, display, etc., and software - which manages the flow of data, and is responsible for data processing and display.

The measuring probe can be either equipped with a skid or remain skidless [24]. This is presented in figure 1. In the latter solution, the reference base is, geometrically, almost an ideal surface. The only part in constant contact with the measured surface is the stylus tip and its vertical displacement is recorded in relation to the reference base area. Skidless probes are well suited for surface texture measurements, as they allow the mapping of all surface components, roughness, waviness and certain form deviations within its

b)

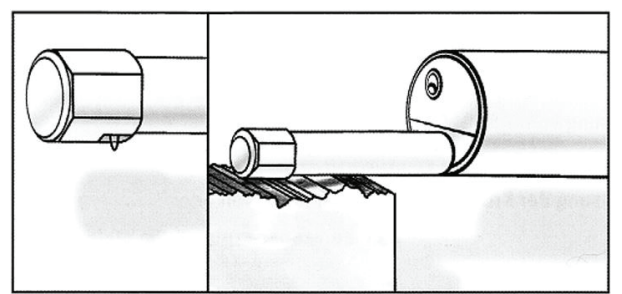

Fig. 1. Visualisation of design solutions for the measuring probe: a) skidless stylus probe, b) probe with a skid [25] 
measurement range. They can be used in a wide scope of applications, from small holes to large scale curvature measurements.

The origin of skid comes from idea of using two different styli that emerged many years ago [26], where one could reproduce roughness and the other waviness. Initially, skid was applied to avoid very expensive manufacturing of guideway, but it also proved to be a good solution in damping the vibrations coming from surroundings. This is done due to a smaller measurement loop than in case of skidless probes. It also serves as mechanical filter and distorts signal coming from a surface, which prevents it from being used in many research applications. Yet, probes with skid are still used in some applications where a workpiece is heavy and the vibrations under workshop conditions are present.

The influence of skid on the values of surface roughness parameters was investigated in references for different surfaces. In their paper, Ishigaki and Kawaguchi concluded that differences are not substantial [27]. It is true for some textures, but there are applications where this influence cannot be neglected. There are also sampling strategies, where the use of skid is questionable [28]. Apart from affecting the results of measurements, a skid may also scratch the measured surfaces. This was reported in literature, by Brown and Savary [29] and Forsyth and Scott [30], where a conclusion was drawn that a damaging action from skid takes place much more often than from a measuring tip. Similar research was also presented by Davis and Stout [31]. There were many different shapes of skids $[32,33]$ that were adopted to various needs and applications.

In a probe with a skid the vertical displacement of the stylus tip is in relation to the vertical displacement of the skid itself. The measurement signal is a difference between these two values. This solution does not require as accurate linear guides. Because of its smaller measurement loop, the presence of a skid makes the system less sensitive to vibrations and complex form deviations of the surface. This, however, may not always produce a desired outcome, as it acts as a form of mechanical filtration.

When a measured profile is irregular (e.g. for abrasive machined surfaces), the distance between the peaks changes very often, resulting in the vertical movement of the skid varying not only in amplitude, but also phase-wise. Despite some peaks being either increased or decreased, in comparison to the calibrated values, the general appearance of the profile and its parameter values will not be significantly altered. It is commonly thought that the influence of the skid on the measurement process and results in a $2 \mathrm{D}$ coordinate system is rather negligible. However, there are certain cases, when the presence of a skid is critical for the evaluation of the results.

The resulting profiles from the measurement with and without a skid are presented in figure 2 . Visible differences, which occur near extreme peaks, will directly affect the calculation of height parameters, which describe the maximum profile features.

The kinematic characteristics of the stylus may be the source of measurement errors. When a stylus is traversed at high speed, the measurement force may not be strong enough to keep the tip down. Under these circumstances, the stylus may lose contact with the surface $[35,36,37,38]$.

The filtering idea of a skid was also tested in some optical devices designed to measure the surface roughness. Mansur et al. [39] presented a device that was a combination of an interferometer (a precise high resolution roughness measuring

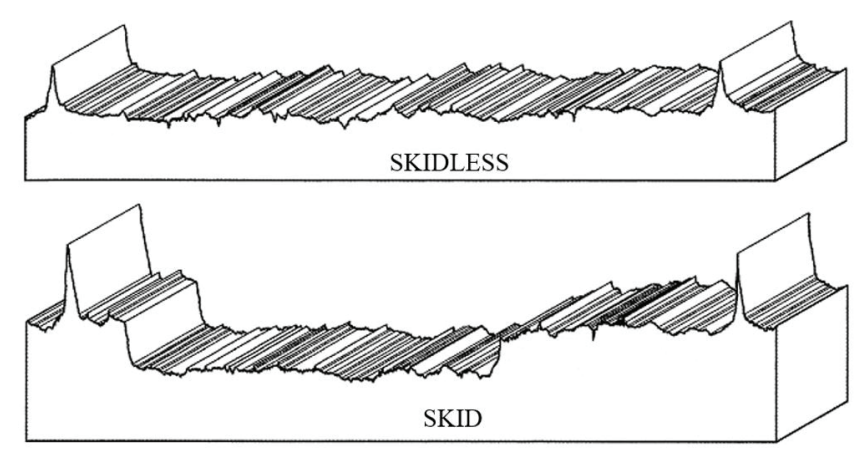

Fig. 2. The comparison of profiles registered while using the skid and the skidless probe [34] 
system) and an autofocussing probe (a skid). The latter was used to tentatively set up a spot coming from a light source. Another idea described in [40] was composed solely of an autofocusing system with two spots: tip - skid. This solution enabled for eliminating the problems with noise detected by optics. Optical skid was also proposed for purely interferometric measurements. Huang [41] presented high sensitivity instrument with two coaxial beams, giving spots with the diameter of $2 \mu \mathrm{m}$ (tip) and $50 \mu \mathrm{m}$ (skid). The dual waves technique was used also later, e.g. for phase-shifting interferometry [42].

Environmental factors play an important role during the surface texture measurements. It is often regarded as a way in which the measuring device is affected, i.e. how well is it isolated from low and high frequency interferences. Low frequency variations are usually caused by thermal fluctuations of the device itself and its surrounding environment. Therefore, the laboratory room should be air conditioned to ensure an allowable gradient of temperature variations over time [43]. These fluctuations are not always gradual, there are cases of direct sunlight affecting the temperature of the device. Another form of interference includes high frequency vibrations, originating either form internal (e.g. stages) or external sources [44].

While most optical methods are sensitive to surface reflexivity, contact stylus profilometry is not. At the same time, due to the aforementioned flight phenomenon, the traverse speed is limited, thus elongating the measurement time, especially when conducting an areal measurement. The application of a skid allows the device to be simplified and enables its use inside production facilities.

\section{METHODOLOGY}

This paper is dedicated to an application where the roughness measurements under workshop conditions are necessary. In the building where hot rolling takes place, temperature conditions vary significantly and vibrations from different sources occur the use of a skid type probe is reasonable.

Railway and tram wheel tyres, as well as rings for heavy duty bearings, are manufactured by means of hot rolling and hot forging. These parts can weigh from $100 \mathrm{~kg}$ to as much as $2500 \mathrm{~kg}$, while its outer dimensions reach from $400 \mathrm{~mm}$ to $1300 \mathrm{~mm}$ in diameter for tyres, and up to $3600 \mathrm{~mm}$ in diameter for rings. Their mass and dimensions make them impossible to measure with a tabletop profilometer, but it is not an obstacle for the use of portable devices (Fig. 3).

Still it is necessary to validate the measurement results obtained by means of a probe with skid, comparing them with those from a skidless one.

As mentioned earlier, the presence of a skid may facilitate the measurement process: however, it may also disrupt the profile acquisition. In order to determine its influence on the measurement results, four measurement systems were evaluated. In this research, comparative measurements of one tabletop and three mobile devices were performed. Three roughness standards (KNT2058-01, KNT2058-03 and KNT2070-03) were used and 50 roughness profiles were measured on each standard. The roughness profiles were analyzed using a Gaussian filter with a value of $0.8 \mathrm{~mm}$. The Mountains Map software was used for data analysis. The measurement a)

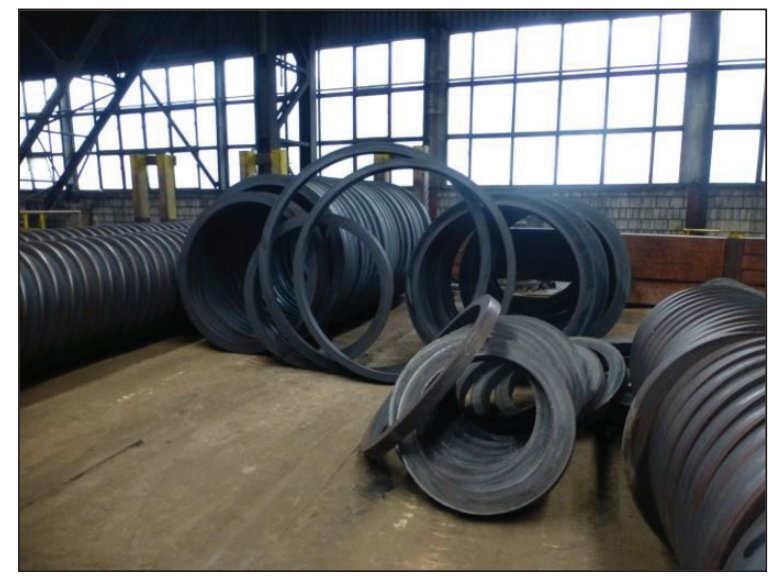

b)

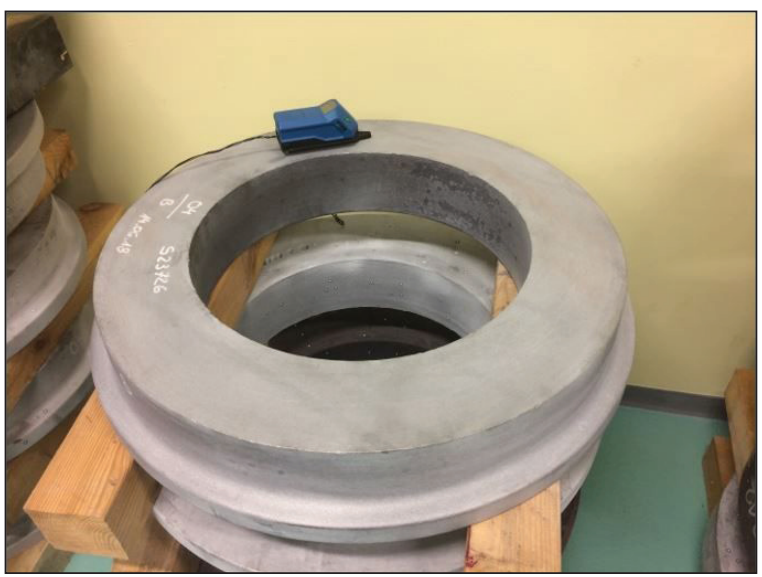

Fig. 3. Railway wheel rings during the measurement with a portable profilometer 
parameters and short profilometers characterisations are presented in Table 1.

Profile roughness parameters, were calculated after each measurement. They included also the ones calculated from a material ratio curve [45]. The resulting data were then subjected to a statistical analysis.

\section{RESULTS}

In order to determine the influence of both the presence of the skid and devices design, three types of D stainless steel standards were measured. The calibrated roughness values are presented in Table 2. Roughness standards type D1 have an irregular profile along the specified traverse direction that repeats every $5 \lambda \mathrm{c}$, for which it is designed. It is mandatory to use only the cut-off value specified in the calibration certificate. This type of standards simulates actual workpieces, since it presents a wide variety of peaks and valleys. It is characterised by the Ra and Rz parameters. Type D2 contains a circular irregular profile.

Fifty measurements of the same profile were performed on each standard. Five roughness parameters, Ra, Rt, Rk, Rpk and Rvk, were selected for further examination. The calculated parameters were then subjected to a statistical analysis. The results are presented in Tables 3-7.

Calculated values of $\mathrm{Ra}$ were also compared between the results from the aforementioned four instruments and are presented in Figure 4.

As seen in Fig. 4a, the mean values of Ra vary significantly when measured with different devices. The least accurate measurements on standard KNT2058-01 were performed using P1 and P2, where $\mathrm{P} 1$ recorded the most dispersed results. Both P3 and P4 did not measure the calibrated value, obtaining either higher or lower values consecutively.

Table 1. Summary of profilometers characteristics and measurement parameters

\begin{tabular}{|c|c|c|}
\hline Profilometer & Short characteristic & Measurement parameters \\
\hline P1 & $\begin{array}{l}\text { Lightweight portable profilometer. Compliance with DIN } 4768 \text { and } \\
\text { ISO } 4287 \text {. Measurement resolution of } 10 \mathrm{~nm} \text { per measuring range of } \\
\pm 20 \mu \mathrm{m} \text {. Standard styli T5E, inductive, carrier frequency } 10 \mathrm{kHz} \text {. Stylus } \\
\text { tip } 5 \mu \mathrm{m} / 90^{\circ} \text {, measuring force } 1.6 \mathrm{mN} \text {. } \\
\text { Skid: } 30 \mathrm{~mm} \text { length, transverse } 1.9 \mathrm{~mm} \text {. }\end{array}$ & $\begin{array}{l}\text { Measuring probe }- \text { T5E } \\
\text { Lt - stylus travel }-4.80 \mathrm{~mm} \\
\text { (for KNT2070-03 Lt }-1.5 \mathrm{~mm} \text { ) } \\
\text { Lc - sampling length }-0.80 \mathrm{~mm} \\
\text { (for KNT2070-03 Lc }-0.25 \mathrm{~mm} \text { ) }\end{array}$ \\
\hline P2 & $\begin{array}{l}\text { Lightweight portable profilometer. Compliance with DIN ISO } 4287 \text {, } \\
\text { DIN EN ISO } 13565 \text {, MOTIF ISO } 12085 \text { and JIS B601. Measurement } \\
\text { resolution of } 6 \mathrm{~nm} \text { in whole measurement range of }-210 \mu \mathrm{m} /+110 \mu \mathrm{m} \text {. } \\
\text { Inductive styli T3E, head with skid, stylus tip } 2 \mu \mathrm{m} / 90^{\circ} \text {. }\end{array}$ & $\begin{array}{l}\text { Measuring probe }- \text { T3E } \\
\text { Lt - stylus travel }-4.80 \mathrm{~mm} \\
\text { (for KNT2070-03 Lt }-1.5 \mathrm{~mm} \text { ) } \\
\text { Lc - sampling length }-0.80 \mathrm{~mm} \\
\text { (for KNT2070-03 Lc }-0.25 \mathrm{~mm} \text { ) }\end{array}$ \\
\hline P3 & $\begin{array}{l}\text { Portable profilometer, skidless, Compliance with DIN ISO 4287, DIN EN } \\
\text { ISO } 13565 \text {, MOTIF ISO } 12085 \text { and JIS B601. Measurement resolution } \\
\text { of } 6 \mathrm{~nm} \text { in whole measurement range of } \pm 300 \mu \mathrm{m} \text {. }\end{array}$ & $\begin{array}{l}\text { Measuring probe }- \text { TKU } \\
\text { Lt - stylus travel }-4.80 \mathrm{~mm} \\
\text { (for KNT2070-03 Lt }-1.5 \mathrm{~mm} \text { ) } \\
\text { Lc - sampling length }-0.80 \mathrm{~mm} \\
\text { (for KNT2070-03 Lc }-0.25 \mathrm{~mm} \text { ) }\end{array}$ \\
\hline P4 & $\begin{array}{l}\text { Tabletop profilometer, skidless. Compliance with DIN ISO } 4287 \text {, DIN EN } \\
\text { ISO } 13565 \text {, MOTIF ISO } 12085 \text { and JIS B601. Measurement resolution } \\
\text { of } 1 \mathrm{~nm} \text { per measurement range of } \pm 8 \mu \mathrm{m} \text {, and } 10 \mathrm{~nm} \text { per } \pm 80 \mu \mathrm{m} \text {. }\end{array}$ & $\begin{array}{l}\text { Measuring probe }- \text { TKU } \\
\text { Lt - stylus travel }-4.80 \mathrm{~mm} \\
\text { (for KNT2070-03 Lt }-1.5 \mathrm{~mm} \text { ) } \\
\text { Lc - sampling length }-0.80 \mathrm{~mm} \\
\text { (for KNT2070-03 Lc }-0.25 \mathrm{~mm} \text { ) }\end{array}$ \\
\hline
\end{tabular}

Table 2. Calibrated roughness values of the standards used in the study

\begin{tabular}{|c|c|c|c|c|}
\hline \multicolumn{2}{|c|}{ Parameter } & \multicolumn{3}{|c|}{ Indication of a standard } \\
\cline { 2 - 5 } & $\mu \mathrm{m}$ & KNT2058-01 & KNT2058-03 & 0.577 \\
\hline $\mathrm{Ra}$ & $\mu \mathrm{m}$ & 1.728 & 4.040 & 0.027 \\
\hline $\mathrm{Rt}$ & $\mu \mathrm{m}$ & 10.850 & 1.655 & 0.089 \\
\hline $\mathrm{Rk}$ & $\mu \mathrm{m}$ & 4.390 & 0.442 & 0.029 \\
\hline $\mathrm{Rpk}$ & $\mu \mathrm{m}$ & 0.445 & 0.984 & 0.035 \\
\hline $\mathrm{Rvk}$ & & 3.620 & & \\
\hline
\end{tabular}


Table 3. Statistical characteristic of profile roughness parameter Ra

\begin{tabular}{|c|c|c|c|c|c|c|c|c|c|c|c|c|}
\hline \multirow{2}{*}{ Parameter } & \multicolumn{4}{|c|}{ KNT2058-01 } & \multicolumn{4}{|c|}{ KNT2058-03 } & \multicolumn{4}{|c|}{ KNT2070-03 } \\
\hline & $\mathrm{P} 1$ & $\mathrm{P} 2$ & P3 & P4 & P1 & $\mathrm{P} 2$ & P3 & P4 & $\mathrm{P} 1$ & $\mathrm{P} 2$ & P3 & P4 \\
\hline mean & 1.811 & 1.829 & 1.742 & 1.720 & 0.657 & 0.632 & 0.583 & 0.570 & 0.030 & 0.028 & 0.028 & 0.030 \\
\hline MAX & 1.850 & 1.834 & 1.745 & 1.722 & 0.660 & 0.666 & 0.584 & 0.571 & 0.031 & 0.030 & 0.028 & 0.031 \\
\hline MIN & 1.800 & 1.823 & 1.739 & 1.718 & 0.640 & 0.612 & 0.581 & 0.569 & 0.028 & 0.027 & 0.027 & 0.029 \\
\hline MAX-MIN & 0.050 & 0.011 & 0.006 & 0.004 & 0.020 & 0.054 & 0.003 & 0.002 & 0.003 & 0.003 & 0.001 & 0.002 \\
\hline standard dev. & 0.018 & 0.002 & 0.002 & 0.001 & 0.007 & 0.016 & 0.001 & 0.001 & 0.001 & 0.001 & 0.0005 & 0.001 \\
\hline skewness & 1.558 & -0 & -0 & -0 & -1 & 0 & 18 & 38 & -2 & 21 & 21 & 414 \\
\hline kurtosis & 0.734 & 0.648 & -0.781 & -1.102 & 1.638 & -0.435 & -0.482 & -1.108 & 6.136 & -0.391 & -1.900 & -0.748 \\
\hline $3 \sigma$ & 0.055 & 0.006 & 0.005 & 0.003 & 0.021 & 0.048 & 0.002 & 0.002 & 0.002 & 0.002 & 0.001 & 0.002 \\
\hline mean $+3 \sigma$ & 1.866 & 1.835 & 1.747 & 1.724 & 0.677 & 0.680 & 0.585 & 0.572 & 0.031 & 0.031 & 0.029 & 0.032 \\
\hline 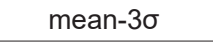 & 1.756 & 1.823 & 1.737 & 1.717 & 0.636 & 0.585 & 0.580 & 0.568 & 0.028 & 0.026 & 0.026 & 0.029 \\
\hline $\mathrm{u}(\mathrm{x})$ (single $\mathrm{m}$. ) & 0.018 & 0.002 & 0.002 & 0.001 & 0.007 & 0.016 & 0.001 & 0.001 & 0.001 & 0.001 & 0.0005 & 0.001 \\
\hline $\mathrm{u}(\mathrm{x})$ (for series) & 0.003 & 0.0003 & 0.0002 & 0.0002 & 0.001 & 0.002 & 0.0001 & 0.0001 & 0.0001 & 0.0001 & 0.0001 & 0.0001 \\
\hline $\mathrm{U}_{095}$ (single $\mathrm{m}$.) & 0.036 & 0.004 & 0.003 & 0.002 & 0.013 & 0.031 & 0.002 & 0.001 & 0.001 & 0.002 & 0.001 & 0.001 \\
\hline$U_{095}$ (for series) & 0.005 & 0.001 & 0.0004 & 0.0003 & 0.002 & 0.004 & 0.0002 & 0.0002 & 0.0001 & 0.0002 & 0.0001 & 0.0001 \\
\hline
\end{tabular}
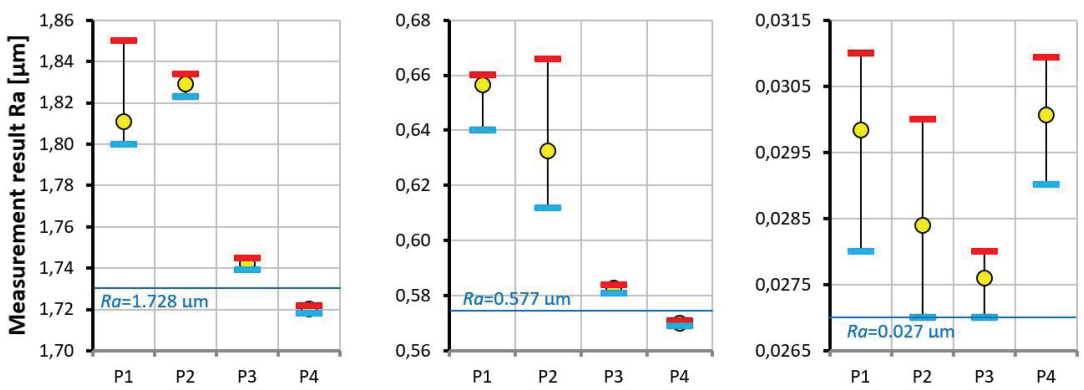

Fig. 4. Comparison of Ra parameter values from P1, P2, P3 and P4 profilometers:

a) for the KNT2058-01 standard, b) for the KNT2058-03 standard, c) for the KNT2070-03 standard

For standard KNT2058-3 the results were overall similar; however, P2 had significantly more dispersed results. The measurements of the third standard recorded the lowest values of the absolute error. The most accurate device was P3, followed closely by P2. P1 did measure the calibrated Ra value, however its results were the most dispersed. P4 recorded results slightly above the calibrated value.

The calculated values of Rt were also compared between the results from the aforementioned four instruments and are presented in Figure 5.

No device measured the exact calibrated value of the first standard (Fig. 5a). There is no clear difference between P1 and P2, both having the highest absolute error. The closest result was obtained using P4.

For the second standard (Fig 5b) the most accurate measurement was performed by P3. The results from $\mathrm{P} 1$ and $\mathrm{P} 2$ were both the highest and most dispersed, as compared to P3 and P4. Surprisingly, the results from $\mathrm{P} 4$ had the second highest absolute error of the mean value. No mean value of measured parameter has met the calibrated value of the third standard; however, for some devices (P1 and $\mathrm{P} 2)$ it was within the extreme measurement values. The calculated values of $\mathrm{Rk}$ were also compared between the results from the aforementioned four instruments and are presented in Figure 6.

Interestingly, only the $\mathrm{P} 1$ device results included the calibrated value of the first standard (Fig. 6a), but at a cost of a significant dispersion on measurement values. Dispersion of results was similar among the other devices; however, only P4 was somewhat close to the calibrated value.

P2 was the only device that managed to measure the exact calibrated value of the second standard (Fig. 6b); however, it was also the minimum value of its series of measurements. When the mean value is considered, $\mathrm{P} 2$ is significantly inaccurate, as well as P1. P3 and P4 have the similar mean value (1.618 and $1.620 \mu \mathrm{m}$, respectively); however, $\mathrm{P} 4$ managed to give 
Table 4. Statistical characteristic of profile roughness parameter Rt

\begin{tabular}{|c|c|c|c|c|c|c|c|c|c|c|c|c|}
\hline \multirow{2}{*}{ Parameter } & \multicolumn{4}{|c|}{ KNT2058-01 } & \multicolumn{4}{|c|}{ KNT2058-03 } & \multicolumn{4}{|c|}{ KNT2070-03 } \\
\hline & $\mathrm{P} 1$ & P2 & P3 & P4 & P1 & P2 & P3 & P4 & $\mathrm{P} 1$ & P2 & P3 & P4 \\
\hline mean & 1.321 & 11.329 & 1.117 & 10.687 & 4.154 & 4.296 & 4.087 & 3.826 & 0.215 & 0.233 & 0.294 & 0.247 \\
\hline MAX & 390 & .387 & 1.164 & 10.740 & 4.220 & 4.449 & 4.138 & 3.880 & 0.230 & 284 & .361 & 0.320 \\
\hline MIN & 1.220 & 11.261 & 11.053 & 10.660 & 4.080 & 4.138 & 4.026 & 3.790 & 0.200 & 0.208 & .212 & 0.220 \\
\hline MAX-MIN & 0.170 & 0.126 & 0.111 & 0.080 & 0.140 & 0.311 & 0.112 & 0.090 & 0.030 & 0.076 & 0.149 & 0.100 \\
\hline standard dev. & 0.035 & 0.023 & 0.024 & 0.018 & 0.038 & 0.080 & 0.024 & 0.018 & 0.008 & 0.019 & 0.038 & 0.024 \\
\hline skewness & 1.022 & -0.092 & -0.076 & 0.674 & -0.119 & 0.088 & -0.220 & 0.330 & -0.240 & 1.021 & -0.479 & 1.152 \\
\hline kurtosis & 1.117 & 1.070 & .076 & 0.283 & -1.166 & -0.958 & 87 & 0.465 & -0.441 & .447 & -0.290 & 0.966 \\
\hline mean3 $\sigma$ & 0.104 & 0.068 & 0.072 & 0.054 & 0.115 & 0.239 & 0.071 & 0.054 & 0.025 & 0.058 & 0.114 & 0.072 \\
\hline mean $+3 \sigma$ & 11.425 & 11.398 & 11.190 & 10.741 & 4.269 & 4.535 & 4.158 & 3.881 & 0.241 & 0.291 & 0.409 & 0.320 \\
\hline 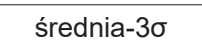 & 11.216 & 11.261 & 11.045 & 10.634 & 4.039 & 4.056 & 4.017 & 3.772 & 0.190 & 0.175 & 0.180 & 0.175 \\
\hline $\mathrm{u}(\mathrm{x})$ (single $\mathrm{m}$. ) & 0.035 & 0.023 & 0.024 & 0.018 & 0.038 & 0.080 & 0.024 & 0.018 & 0.008 & 0.019 & 0.038 & 0.024 \\
\hline $\mathrm{u}(\mathrm{x})$ (for series) & 0.005 & 0.003 & 0.003 & 0.003 & 0.005 & 0.011 & 0.003 & 0.003 & 0.001 & 0.003 & 0.005 & 0.003 \\
\hline $\mathrm{U}_{095}$ (single $\mathrm{m}$ & 0.068 & 0.045 & 0.047 & 0.035 & 0.075 & 0.156 & 0.046 & 0.036 & 0.016 & 0.038 & 0.075 & 0.047 \\
\hline$U_{095}$ (for series) & 0.010 & 0.006 & 0.007 & 0.005 & 0.011 & 0.022 & 0.007 & 0.005 & 0.002 & 0.005 & 0.011 & 0.007 \\
\hline
\end{tabular}
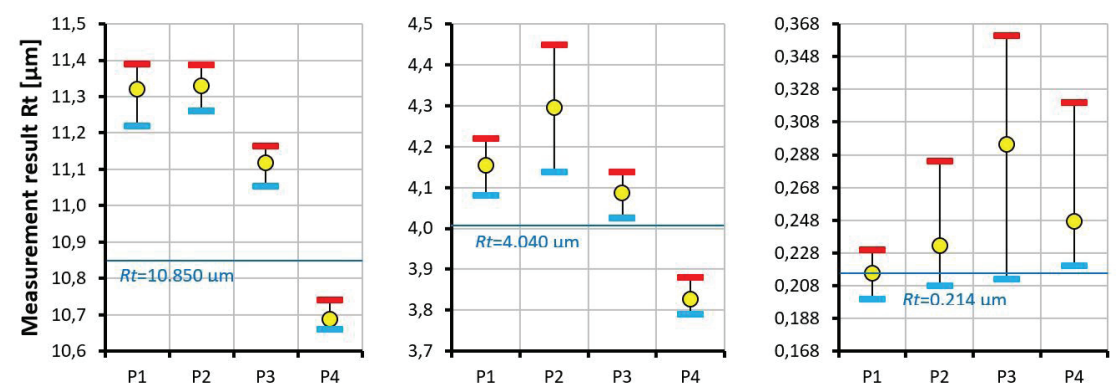

Fig. 5. Comparison of Rt parameter values from $\mathrm{P} 1, \mathrm{P} 2, \mathrm{P} 3$ and $\mathrm{P} 4$ :

a) for the KNT2058-01 standard, b) for the KNT2058-03 standard, c) for the KNT2070-03 standard
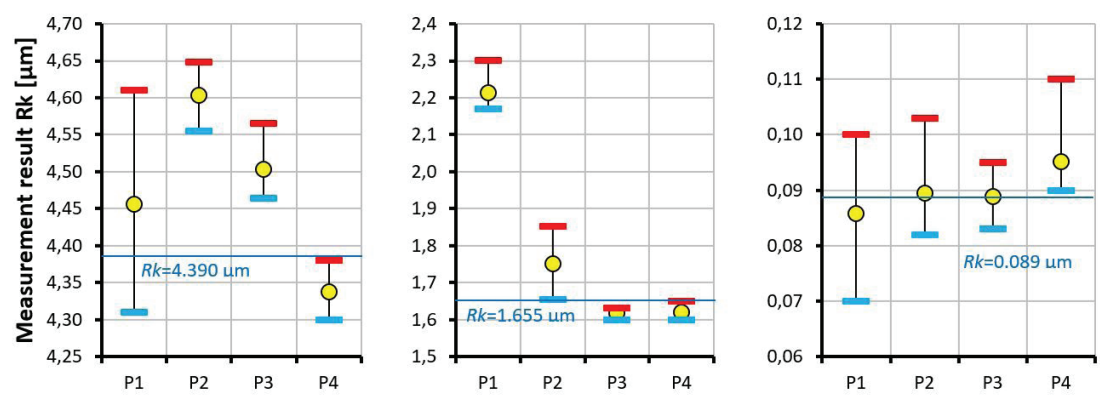

Fig. 6. Comparison of the Rk parameter values from P1, P2, P3 and P4:

a) for the KNT2058-01 standard, b) for the KNT2058-03 standard, c) for the KNT2070-03 standard

the results slightly closer to the calibrated value. All devices measured the value of Rk relatively well on the third standard (Fig. 6c) with no significant deviations. However, there is a noticeable dispersion of the results from $\mathrm{P} 1$. The calculated values of Rpk were also compared between the results from the aforementioned four instruments and are presented in Figure 7.
No device measured the exact calibrated value of the KNT2058-01. While the results from all skidless devices were below the calibrated threshold, the P1 device registered the values nearly twice as high. Interestingly, this was not the case for the second standard (Fig. 7b), where all devices measured values below the threshold. For this standard, the most accurate measurements were performed with the P3 device. 
Table 5. Statistical characteristic of profile roughness parameter Rk

\begin{tabular}{|c|c|c|c|c|c|c|c|c|c|c|c|c|}
\hline \multirow{2}{*}{ Parameter } & \multicolumn{4}{|c|}{ KNT2058-01 } & \multicolumn{4}{|c|}{ KNT2058-03 } & \multicolumn{4}{|c|}{ KNT2070-03 } \\
\hline & $\mathrm{P} 1$ & $\mathrm{P} 2$ & P3 & P4 & $\mathrm{P} 1$ & $\mathrm{P} 2$ & P3 & P4 & $\mathrm{P} 1$ & $\mathrm{P} 2$ & P3 & P4 \\
\hline mean & 4.457 & 4.603 & 4.503 & 4.337 & 2.214 & 1.752 & 1.618 & 1.620 & 0.086 & 0.090 & 0.089 & 0.095 \\
\hline MAX & 4.610 & 4.648 & 4.565 & 4.380 & 2.300 & 1.853 & 1.631 & 1.650 & 0.100 & 0.103 & 0.095 & 0.110 \\
\hline MIN & 4.310 & 4.555 & 4.464 & 4.300 & 2.170 & 1.655 & 1.600 & 1.600 & 0.070 & 0.082 & 0.083 & 0.090 \\
\hline MAX-MIN & 0.300 & 0.093 & 0.101 & 0.080 & 0.130 & 0.198 & 0.031 & 0.050 & 0.030 & 0.021 & 0.012 & 0.020 \\
\hline standard dev. & 0.097 & 0.020 & 0.024 & 0.023 & 0.031 & 0.054 & 0.008 & 0.015 & 0.006 & 0.005 & 0.003 & 0.005 \\
\hline skewness & 0.097 & -0.118 & 0.478 & 0. & 3 & 48 & 48 & 0.470 & 01 & 0.647 & 21 & 0.315 \\
\hline kurtosis & -1.276 & -0.112 & -0.246 & -0.971 & 0.304 & -0.970 & -0.374 & -0.767 & 0.070 & -0.097 & 0.598 & -1.106 \\
\hline $3 \sigma$ & 0.292 & 0.059 & 0.072 & 0.068 & 0.092 & 0.162 & 0.023 & 0.046 & 0.018 & 0.015 & 0.008 & 0.016 \\
\hline mean $+3 \sigma$ & 4.749 & 4.662 & 4.575 & 4.405 & 2.306 & 1.914 & 1.641 & 1.666 & 0.104 & 0.105 & 0.097 & 0.112 \\
\hline 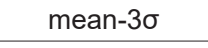 & 4.164 & 4.544 & 4.432 & 4.269 & 2.122 & 1.590 & 1.594 & 1.575 & 0.068 & 0.074 & 0.081 & 0.079 \\
\hline $\mathrm{u}(\mathrm{x})$ (single $\mathrm{m}$. ) & 0.097 & 0.020 & 0.024 & 0.023 & 0.031 & 0.054 & 0.008 & 0.015 & 0.006 & 0.005 & 0.003 & 0.005 \\
\hline $\mathrm{u}(\mathrm{x})$ (for series) & 0.014 & 0.003 & 0.003 & 0.003 & 0.004 & 0.008 & 0.001 & 0.002 & 0.001 & 0.001 & 0.0004 & 0.001 \\
\hline $\mathrm{U}_{095}$ (single $\mathrm{m}$.) & 0.191 & 0.039 & 0.047 & 0.044 & 0.060 & 0.106 & 0.015 & 0.030 & 0.012 & 0.010 & 0.005 & 0.011 \\
\hline$U_{095}$ (for series) & 0.027 & 0.005 & 0.007 & 0.006 & 0.009 & 0.015 & 0.002 & 0.004 & 0.002 & 0.001 & 0.001 & 0.002 \\
\hline
\end{tabular}
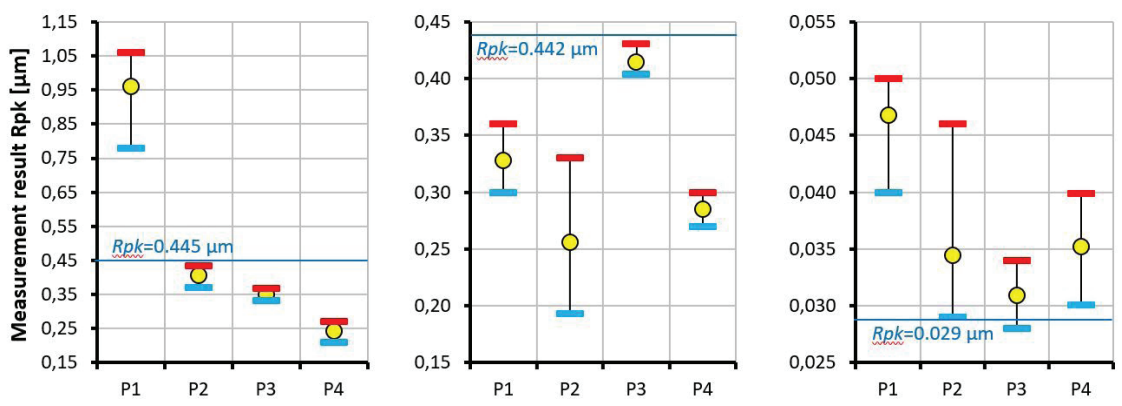

Fig. 7. Comparison of parameter Rpk values from P1, P2, P3 and P4:

a) for the KNT2058-01 standard, b) for the KNT2058-03 standard, c) for the KNT2070-03 standard

For the third standard (Fig. 7c), the average values from all devices were relatively close to the calibrated value; however, all were above the threshold. P1 and P4 recorded the highest absolute error for the average value. The calculated values of Rvk were also compared between the results from the aforementioned four instruments and are presented in Figure 8.
A seen in Figure 8a, the most accurate measurements, considering only average values, were performed using the P1 device; however, they were also the least repeatable. All other devices recorded values below the calibrated threshold, with P4 having the largest absolute error.

For the second standard (Fig. 8b), all measured values, except for P2, were slightly below
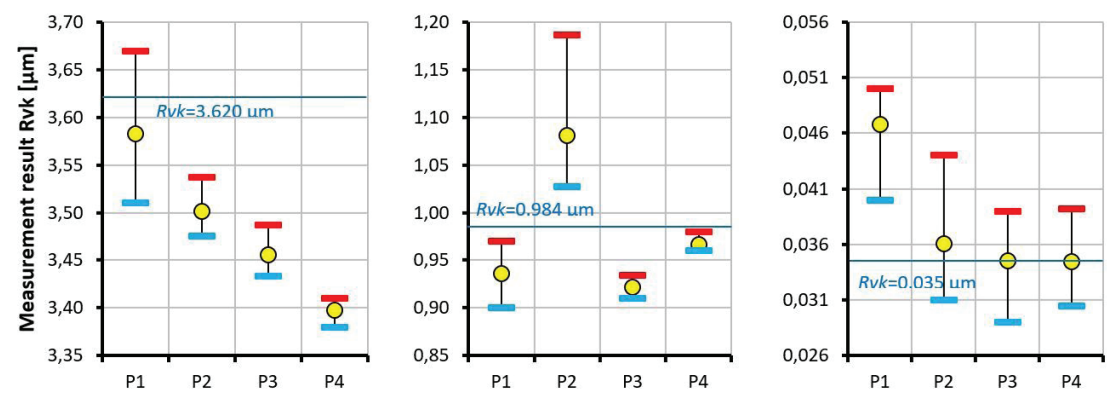

Fig. 8. Comparison of parameter Rvk values from profilometers $\mathrm{P} 1, \mathrm{P} 2, \mathrm{P} 3$ and $\mathrm{P} 4$ : a) for the KNT2058-01 standard, b) for the KNT2058-03 standard, c) for the KNT2070-03 standard 
Table 6. Statistical characteristic of profile roughness parameter Rpk

\begin{tabular}{|c|c|c|c|c|c|c|c|c|c|c|c|c|}
\hline \multirow{2}{*}{ Parameter } & \multicolumn{4}{|c|}{ KNT2058-01 } & \multicolumn{4}{|c|}{ KNT2058-03 } & \multicolumn{4}{|c|}{ KNT2070-03 } \\
\hline & P1 & P2 & P3 & P4 & P1 & P2 & P3 & P4 & P1 & P2 & P3 & P4 \\
\hline mean & 0.960 & 0.405 & 0.350 & 0.241 & 0.328 & 0.256 & 0.415 & 0.285 & 0.047 & 0.034 & 0.031 & 0.035 \\
\hline MAX & 1.060 & 0.433 & 0.368 & 0.270 & 0.360 & 0.330 & 0.431 & 0.300 & 0.050 & 0.046 & 0.034 & 0.040 \\
\hline MIN & 0.780 & 0.370 & 0.332 & 0.210 & 0.300 & 0.193 & 0.404 & 0.270 & 0.040 & 0.029 & 0.028 & 0.030 \\
\hline MAX-MIN & 0.280 & 0.063 & 0.036 & 0.060 & 0.060 & 0.137 & 0.027 & 0.030 & 0.010 & 0.017 & 0.006 & 0.010 \\
\hline standard dev. & 0.076 & 0.012 & 0.008 & 0.015 & 0.014 & 0.033 & 0.006 & 0.008 & 0.005 & 0.004 & 0.001 & 0.003 \\
\hline skewness & -1.257 & -0.519 & 0.021 & -0.064 & -0.040 & 0.255 & 0.300 & -0.390 & -0.796 & 0.964 & 0.008 & -0.129 \\
\hline kurtosis & 0.418 & 1.394 & -0.190 & -0.905 & -0.483 & -0.316 & 0.436 & -0.328 & -1.425 & 0.692 & -0.527 & -1.368 \\
\hline $3 \sigma$ & 0.229 & 0.035 & 0.025 & 0.045 & 0.043 & 0.099 & 0.017 & 0.024 & 0.014 & 0.012 & 0.004 & 0.010 \\
\hline mean $+3 \sigma$ & 1.189 & 0.439 & 0.375 & 0.286 & 0.370 & 0.354 & 0.432 & 0.309 & 0.061 & 0.046 & 0.035 & 0.045 \\
\hline 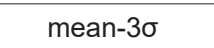 & 0.731 & 0.370 & 0.325 & 0.196 & 0.285 & 0.157 & 0.398 & 0.261 & 0.033 & 0.023 & 0.027 & 0.025 \\
\hline $\mathrm{u}(\mathrm{x})$ (single $\mathrm{m}$. ) & 0.076 & 0.012 & 0.008 & 0.015 & 0.014 & 0.033 & 0.006 & 0.008 & 0.005 & 0.004 & 0.001 & 0.003 \\
\hline $\mathrm{u}(\mathrm{x})$ (for series) & 0.011 & 0.002 & 0.001 & 0.002 & 0.002 & 0.005 & 0.001 & 0.001 & 0.001 & 0.001 & 0.0002 & 0.0005 \\
\hline $\mathrm{U}_{095}$ (single m.) & 0.150 & 0.023 & 0.016 & 0.029 & 0.028 & 0.064 & 0.011 & 0.015 & 0.009 & 0.008 & 0.003 & 0.006 \\
\hline $\mathrm{U}_{095}$ (for series) & 0.021 & 0.003 & 0.002 & 0.004 & 0.004 & 0.009 & 0.002 & 0.002 & 0.001 & 0.001 & 0.0004 & 0.001 \\
\hline
\end{tabular}

Table 7. Statistical characteristic of profile roughness parameter Rvk

\begin{tabular}{|c|c|c|c|c|c|c|c|c|c|c|c|c|}
\hline \multirow{2}{*}{ arameter } & \multicolumn{4}{|c|}{ KNT2058-01 } & \multicolumn{4}{|c|}{ KNT2058-03 } & \multicolumn{4}{|c|}{ KNT2070-03 } \\
\hline & $\mathrm{P} 1$ & P2 & P3 & P4 & P1 & P2 & P3 & P4 & $\mathrm{P} 1$ & $\mathrm{P} 2$ & P3 & P4 \\
\hline mean & 3.583 & 3.501 & 456 & 3.397 & 0.936 & 1.081 & 0.921 & 0.967 & 0.047 & 0.036 & 0.035 & 0.034 \\
\hline MAX & 3.670 & 3.537 & 3.487 & 3.410 & 970 & 1.187 & 934 & 0.980 & .050 & .044 & .039 & 039 \\
\hline MIN & 3.510 & 3.475 & 3.433 & 3.380 & 0.900 & 1.027 & 0.910 & 0.960 & 0.040 & 31 & 0.029 & 0.030 \\
\hline MAX-MIN & 0.160 & 0.062 & 0.054 & 0.030 & 0.070 & 0.160 & 0.024 & 0.020 & 0.010 & 0.013 & 0.010 & 0.009 \\
\hline standard dev. & 0.047 & 0.015 & 0.013 & 0.006 & 0.016 & 0.046 & 0.006 & 0.006 & 0.005 & 0.003 & 0.002 & 0.003 \\
\hline skewness & 0.112 & 0.098 & 0.628 & -0.236 & -0.176 & 0.916 & 0.129 & 0.194 & -0.796 & 0.641 & -0.245 & 0.172 \\
\hline kurtosis & -1.416 & -0.258 & 0.170 & 0.244 & -0.613 & -0.397 & -0.458 & -0.576 & -1.425 & 0.193 & 0.225 & -1.032 \\
\hline $3 \sigma$ & 0.142 & 0.044 & 0.038 & 0.019 & 0.049 & 0.138 & 0.017 & 0.018 & 0.014 & 0.009 & 0.007 & 0.008 \\
\hline mean $+3 \sigma$ & 3. & 3.545 & 3.493 & 3.4 & 5 & 1.219 & 39 & 0. & 61 & 0.045 & 0.041 & 0.042 \\
\hline mean-3 $\sigma$ & 3.441 & 3.457 & 3.418 & 3.378 & 0.887 & 0.943 & 0.904 & 0.949 & 0.033 & 0.027 & 0.028 & 0.026 \\
\hline $\mathrm{u}(\mathrm{x})$ (single $\mathrm{m}$. ) & 0.047 & 0.015 & 0.013 & 0.006 & 0.016 & 0.046 & 0.006 & 0.006 & 0.005 & 0.003 & 0.002 & 0.003 \\
\hline $\mathrm{u}(\mathrm{x})$ (for series) & 0.007 & 0.002 & 0.002 & 0.001 & 0.002 & 0.007 & 0.001 & 0.001 & 0.001 & 0.000 & 0.0003 & 0.0004 \\
\hline $\mathrm{U}_{095}$ (single $\mathrm{m}$.) & 0.093 & 0.029 & 0.025 & 0.012 & 0.032 & 0.090 & 0.011 & 0.012 & 0.009 & 0.006 & 0.004 & 0.005 \\
\hline$U_{095}$ (for series) & 0.013 & 0.004 & 0.003 & 0.002 & 0.005 & 0.013 & 0.002 & 0.002 & 0.001 & 0.001 & 0.001 & 0.001 \\
\hline
\end{tabular}

the calibrated value. The P2 measurements were also the least repeatable. Measurements performed on the third standard were both the most accurate and most repeatable. Only slight deviations were registered. The values from the P1 device were slightly higher than the calibrated value.

In order to conduct a quantitative assessment of individual roughness parameters obtained using the aforementioned methods, a relative error $\delta$ was calculated for each measuring device and standard (1). This error is expressed as a ratio of an absolute error of the measurement to the true value of the parameter being measured.

$$
\delta=\frac{\overline{\operatorname{Ra}(\text { Rmax })}_{(\text {Device })}-\overline{\operatorname{Ra}(\operatorname{Rmax})}_{(\mathrm{std})}}{\overline{\operatorname{Ra}(\operatorname{Rmax})_{(\mathrm{std})}}} \cdot 100 \%
$$

where: mean value of roughness parameters obtained by the use of a proper device ( $\mathrm{P} 1$, $\mathrm{P} 2, \mathrm{P} 3$ or $\mathrm{P} 4)$ for 50 repetitions, mean value of roughness parameters given by the manufacturer of roughness standards.

The calculated values are shown in diagrams (Fig. 9-11).

As seen in Figure 9, the relative error for parameter Rpk stands out significantly for all measuring devices. The lowest value was reached in 


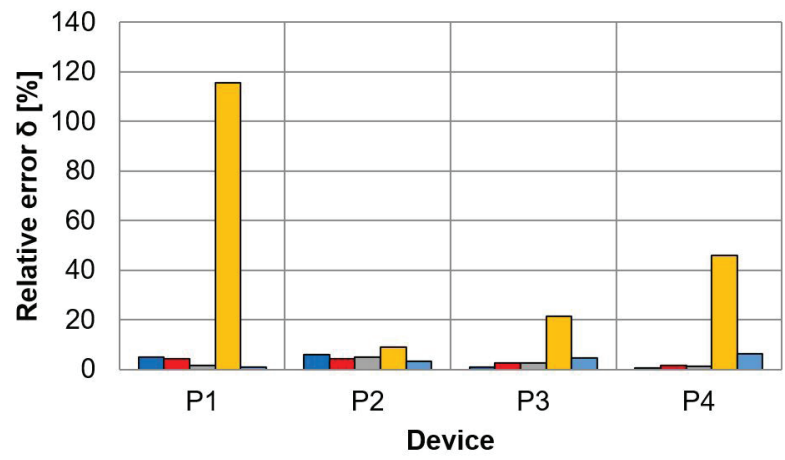

$\square \mathrm{Ra} \square \mathrm{Rt} \quad \square \mathrm{Rk} \quad \square \mathrm{Rpk} \quad \square \mathrm{Rvk}$

Fig. 9. Comparison of relative errors of the mean value of roughness parameters obtained for the devices P1, P2, P3 and P4 - for the KNT2058-01 standard

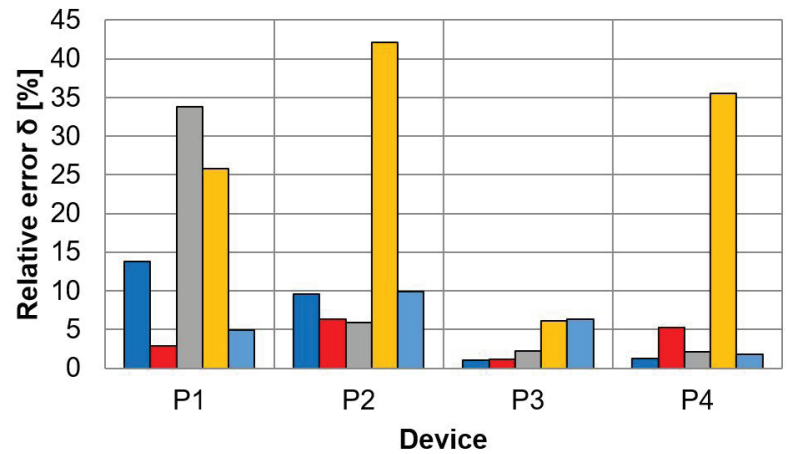

$\square \mathrm{Ra} \quad \square \mathrm{Rt} \quad \square \mathrm{Rk} \quad \square \mathrm{Rpk} \quad \square \mathrm{Rvk}$

Fig. 10. Comparison of relative errors of the average value of roughness parameters obtained for the P1, P2, P3 and P4 devices - for the KNT2058-03 standard

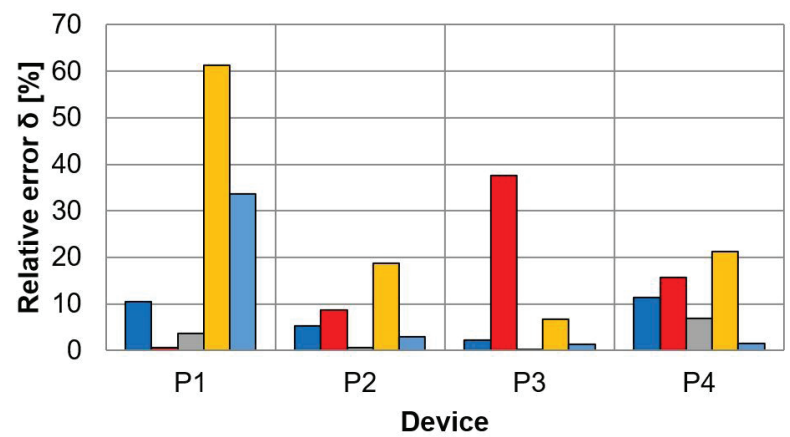

$\square$ Ra $\square$ Rt $\square$ Rk $\square$ Rpk $\square$ Rvk

Fig. 11. Comparison of relative errors of the average value of roughness parameters obtained for the P1, P2, P3 and P4 devices - for the KNT2070-03 standard

device P2. This device, however, had the highest relative error for the Ra, Rt and Rk parameters. The relative error for the Rvk parameter is nearly negligible for all devices, except P4. Similarly, the relative error of $\mathrm{Rk}$ is kept very low in all devices, except for P2. P1 and P2 have similar relative errors for the Ra parameter, while in $\mathrm{P} 3$ and $\mathrm{P} 4$, its value is almost zero.

As seen in Figure 10, regarding KNT2058-03 standard, the overall relative errors reach the highest values for the Rpk parameter. The only exception, where relative error is below $10 \%$, is 
the P3 device. The Ra parameter was measured with almost negligible relative error using the $\mathrm{P} 3$ and $\mathrm{P} 4$ devices. The Rt parameter reached the values of approximately 5\% in the P2 and P4 measurements. Relative error of Rk was significantly higher in the P1 measurements, nearly $35 \%$, compared to other devices (approx. 5\% and lower). Rvk was measured with the lowest relative error using P4, and reached highest values when measured with P2.

The relative error (Fig. 11) of the Ra parameter exceeded $10 \%$ only in P1 and P4. The relative error of Rt was negligible in the P1 device, and reached the highest value when measured with $\mathrm{P} 3$. Its value in P4 also exceeded a threshold of $10 \%$. Rk is the most accurately measured parameter in this setup. It is negligible in $\mathrm{P} 2$ and $\mathrm{P} 3$, and is well below the $10 \%$ threshold in other devices. Rpk had the highest relative error value in all devices, except P3. Rvk was measured very accurately with all skidless devices (P2, P3 and P4), but reached a level of over $30 \%$ when measured with a skid.

Relative errors of the parameters presented in the graphs may be caused (depending on the type of device) used drive, gear or other mechanical components, which may indirectly determines into the movement of the measuring tip. A probable factor in the occurrence of deviations from the expected values may also be the influence of environmental conditions, such as temperature or vibrations that may have occurred during the measurement. Depending on the represented topography parameter, the influence of individual factors determines the value of the relative error.

\section{CONCLUSIONS}

For the purpose of this study, a series of measurements were performed using four different contact stylus profilometers. Three type D roughness standards were chosen, and each was measured with all four devices. Five roughness parameters (Ra, Rt, Rk, Rpk and Rvk) were chosen for further evaluation and were subjected to a statistical analysis.

The presented results of the measurements clearly indicate that for the older type of contact stylus profilometer ( $\mathrm{P} 1$, skid) there is a slight dispersion of the obtained values. This is caused by the aforementioned flaws in its design, and worse resolution as compared to the other device. This results in a relatively larger dispersion of measured values, especially for "average value" parameters, such as Ra.

Other skidless portable devices, P2 and P3, have a better measurement resolution, which results in a noticeably lower dispersion of measured values. A tabletop device utilizes a skidless measuring probe. It has both the best resolution and the highest rigidity, which results in a lower dispersion of measured values.

It was noticed that the overall lowest relative error was achieved when measuring the KNT2058-03 roughness standard with the P3 device. In the case of the other standard, KNT2070-03, which has the lowest roughness values, the lowest relative error of the Ra parameter was determined for P2 (9.2\%) and, interestingly, the highest was determined for P3 (72.6\%). A comparative analysis of mean, maximum and minimum values of this parameter confirms the aforementioned observations.

\section{Acknowledgments}

The presented research was conducted within the task "Analysis of the influence of the surface preparation process on the measurement uncertainty of geometrical features of rings and rims" realized within a project No. POIR.01.01.01-00-0208/17, entitled: “Automated line for quality control and examination of rings and rims, with an intelligent system of identification and measurement of internal defects using the PA method, form measurement by means of 3D measurement heads, and inspection of mechanical properties SMART-HARD", realized by Huta Bankowa Sp. z o.o. within the Smart Growth Operational Program 2014-2020. Priority Axis I: Support for R\&D activity of enterprises. Investment Priority $1 b$ : R\&D projects of enterprises.

The research results were funded with the education grants allocated by the Ministry of Science and Higher Education in Poland No. 0614/ $\mathrm{SBAD} / 1529$.

\section{REFERENCES}

1. Gadelmawla E.S., Koura M.M., Maksoud T.M.A., Elewa I.M., Soliman H.H. Roughness parameters. Journal of Materials Processing Technology. 2002; 123(1): 133-145.

2. Wieczorowski M., Mrozek R., Andrałojć P. The use of surface asperities analysis to investigate wear of bodies in contact on example of brake 
elements. Metrology and Measurement Systems. 2010; 17(2): 271-278.

3. Tay F., Sumit Kanti S., Mannan M.A. Topography of the flank wear surface. Journal of Materials Processing Technology. 2002; 120(1-3): 243-248.

4. Varga G., Sovilj B., Jakubowicz M., Babič M. Experimental Examination of Surface Roughness in Low-Environmental-Load Machining of External Cylindrical Workpieces. Advances in Manufacturing. 6th International Scientific-Technical Conference Manufacturing, 19-22.05, Poznan, Poland 2019, 307-321.

5. Jeng Y.R., Lin Z.W., Shyu S.H. Changes of Surface Topography During Running-In Process. Journal of Tribology. 2004; 126(3): 620-625.

6. Twardowski P., Wojciechowski S., Wieczorowski M., Mathia T. Surface roughness analysis of hardened steel after high speed milling. Scanning. 2011; 33(5): 386-395.

7. Chen Y.K., Kukureka S.N., Hooke C.J., Rao M. Surface topography and wear mechanisms in polyamide 66 and its composites. Journal of Materials Science. 2000; 35(5): 1269-1281.

8. Pawlus P., Reizer R., Wieczorowski M. Reverse Problem in Surface Texture Analysis One-Process Profile Modeling on the Basis of Measured Two-Process Profile after Machining or Wear. Materials. 2019; 12(24): 4169.

9. Sayles R.A., Thomas T.R. Mapping a small area of a surface. J. Phys. E. 1976; 9(10), 855-861.

10. Williamson J.B.P. The microtopography of surfaces. Proc. I. Mech. E. 1967; 182: 21-30.

11. Myshkin N.K., Grigoriev A., Chizhik S.A., Choi K.Y., Petrokovets M.I. Surface roughness and texture analysis in microscale. Wear. 2003; 254(10): 1001-1009.

12. Teague E.C., Scire F.E., Baker S.M., Jensen S.W. Three-dimensional stylus profilometry. Wear. 1982; 83(1): 1-12.

13. Mathia T.G., Pawlus P., Wieczorowski M. Recent trends in surface metrology. Wear. 2011; 271(3-4): 494-508.

14. De Groot P. The Meaning and Measure of Vertical Resolution in Optical Surface Topography Measurement. Applied Sciences. 2017; 7(1): 54.

15. Foreman M.R., Giusca C., Coupland J., Török P., Leach R. Determination of the transfer function for optical surface topography measuring instruments - a review. Measurement Science and Technology. 2013; 24(5): 052001.

16. Gomez C., Su R., De Groot P., Leach R. Noise Reduction in Coherence Scanning Interferometry for Surface Topography Measurement, Nanomanufacturing and Metrology. 2020; 3: 68-76.
17. Kucharski D., Zdunek H. Optical setup for a fast scatterometry surface texture measurements with nanometric precision. Bulletin of the Polish Academy of Sciences: Technical Sciences. 2020; 68(3): 485-490.

18. Grochalski K., Wieczorowski M., H'Roura J., Le Gioc G. The optical aspect of errors in measurements of surface asperities using the optical profilometry method. Frontiers in Mechanical Engineering. 2020; 6(12): 1-11.

19. Pawlus P., Reizer R., Wieczorowski M. Comparison of the results of surface texture measurement by stylus methods and optical methods. Metrology and Measurement Systems. 2018; 25(3): 589-602.

20. Grochalski K., Wieczorowski M., Pawlus P., H'Roura J. Thermal Sources of Errors in Surface Texture Imaging. Materials. 2020; 13(10): 2337-1 - 2337-18.

21. Whitehouse D.J. Theoretical analysis of stylus integration. Annals CIRP. 1974; 23(1): 181-182.

22. Pawlus P. Mechanical filtration of surface profiles. Measurement. 2004; 35(4): 325-341;

23. Abbott E.J., Bousky S., Williamson D.E. The profilometer. Mechanical Engineering. 1938; 60: 205-216.

24. Bellantonio M. On the risks associated with wear quantification using profilometers equipped with skid tracers. Friction. 2016; (1): 84-88.

25. Mummery L. Surface Texture Analysis The Handbook, B004301P201992; 1992.

26. Way S. Description and observation of metal surfaces, Proc. Conf. Frict. Surf. Finish, 2e, MIT, Cambridge, England 1969: 44-75.

27. Ishigaki H., Kawaguchi I. Effect of a skid on the accuracy of measuring surface roughness. Wear. 1981; 68(2): 203-211.

28. Wieczorowski M. Spiral sampling as a fast way of data acquisition in surface topography. Int. J. Mach. T. Manuf. 2001; 41(13-14): 2017-2022.

29. Brown C.A., Savary G. Describing ground surface texture using contact profilometry and fractal analysis. Wear. 1991; 141(2): 221-226.

30. Forsyth I., Scott D. Characterization of micromachined mirror surfaces from high speed diamond fly cutting. Wear. 1982; 83(2): 251-263.

31. Davis E.J., Stout K.J. Stylus measurement techniques: A contribution to the problem of parameter variation. Wear. 1982; 83(1): 49-60;

32. Farago F.T. Handbook of dimensional measurement, Industrial Press, New York; 1982.

33. Hunter A.G.M., Smith E.A. Measurement of surface roughness. Wear. 1980; 59(2): 383-386.

34. Volk R., Rauheitsmessung: Theorie und Praxis, Beuth; 2005. 
35. Fang H, Xu B, Yin D, Zhao S. A. Method to Control Dynamic Errors of the Stylus-Based Probing System for the Surface Form Measurement of Microstructures. Journal of Nanomaterials. 2016; 2016: 1-8.

36. Thomsen-Schmidt P. Development of a new stylus contacting system for roughness measurement. Proc. XI Coll. Surf., Chemnitz, Germany 2004, 79-85.

37. Pawlus P., Smieszek M. The influence of stylus flight on change of surface topography parameters. Precision Engineering. 2005; 29(3): 272-280.

38. McCool J.I. Assessing the effect of stylus tip radius and flight on surface topography measurements. Trans. ASME: J. Trib. 1984; 106(2): 202-210.

39. Mansur D.J., Voorhes D.W., Wyntjes G.J. Laser surface profilometer with subangstrom resolution. Proc. SPIE. 1992; 1673: 403-413.

40. Fainman Y., Lenz E., Shamir J. Optical profilometer: a new method for high sensitivity and wide dynamic range. Appl. Opt. 1982; 21(17): 3200-3208.

41. Huang C.C. Optical heterodyne profilometer. Proc. SPIE. 1983; 429: 65-74.
42. Liu Q., Li L., Zhang H., Huang W., Yue X. Simultaneous dual-wavelength phase-shifting interferometry for surface topography measurement. Optics and Lasers in Engineering. 2020; 124: 105813.

43. Miller T., Adamczak S., Świderski J., Wieczorowski M., Łętocha A., Gapiński B. Influence of temperature gradient on surface texture measurements with the use of profilometry. Bulletin of the Polish Academy of Sciences. Technical Sciences. 2017; 65(1): 53-61.

44. Zelinka J., Čepová L. Gapiński B, Čep R., Mizera O., Hrubý R. The Effect of a Stylus Tip on Roundness Deviation with Different Roughness. Advances in Manufacturing. 6th International Scientific-Technical Conference Manufacturing, 19-22.05, Poznan, Poland 2019, 147-157.

45. Pawlus P., Reizer R., Wieczorowski M., Królczyk G. Material ratio curve as information on the state of surface topography - A review. Precision Engineering. 2020; 65: 240-258.

46. ISO 5436-1:2000 Geometrical Product Specifications (GPS) - Surface texture: Profile method; Measurement standards - Part 1: Material measures. 